\title{
FASES DE TRANSIÇÃO DA CARREIRA ESPORTIVA: PERSPECTIVA DE EX-ATLETAS PROFISSIONAIS DO FUTEBOL BRASILEIRO
}

\author{
Varley Teoldo da Costa, Centro Universitário de Belo Horizonte - UNI-BH - Belo Horizonte, \\ Minas Gerais - Brasil \\ Renato Melo Ferreira, Universidade Federal de Minas Gerais - UFMG - Belo Horizonte, Minas \\ Gerais - Brasil \\ Eduardo Macedo Penna, Universidade Federal de Minas Gerais - UFMG - Belo Horizonte, \\ Minas Gerais - Brasil \\ Israel Teoldo da Costa, Universidade Federal de Viçosa - UFV - Viçosa, Minas Gerais - Brasil \\ Tatiana Natalina Silva Paiva, Centro Universitário de Belo Horizonte - UNI-BH - Belo \\ Horizonte, Minas Gerais - Brasil \\ Dietmar Martin Samulski, Universidade Federal de Minas Gerais - UFMG - Belo Horizonte, \\ Minas Gerais - Brasil
}

\section{RESUMO}

Considerado como a principal modalidade esportiva do país, o futebol pode ser praticado por pessoas de todas as idades e níveis sociais. Sua prática voluntária e plurianual é constituída de diferentes fases de desenvolvimento durante a carreira dos atletas. Essas fases apresentam características específicas em relação às interferências existentes entre o ambiente e o atleta. $\mathrm{O}$ objetivo do estudo foi investigar, de forma retrospectiva, os principais aspectos relacionados à cada fase de transição da carreira esportiva de ex-atletas de futebol. Durante as fases de desenvolvimento, o apoio da família, as dificuldades encontradas para a continuidade da prática e a preocupação com o planejamento da carreira esportiva foram destacadas como importantes no processo de desenvolvimento esportivo. Concluiu-se que o desenvolvimento da carreira dos atletas foi assistido, em todas as fases, pelo apoio (financeiro e / ou motivacional) de suas famílias.

Palavras-Chave: Fases de desenvolvimento; Carreira esportiva; Futebol.

\section{PHASES OF TRANSISTION OF CAREER ESPORTIVA: PERSPECTIVE OF PROFESSIONAL EX-ATLETAS OF THE BRAZILIAN SOCCER}

\begin{abstract}
Considered the principal sport of the country, soccer can be played by people of all ages and levels of socioeconomic status. The voluntary practice of the sport along the years has been formed from different phases of development during the athlete's careers. These phases have shown specific characteristics in relation to the interference that exists between the ambient and the athlete. The aim of the study was to retrospectively investigate the main aspects of the ex-athlete's career and how that has related to his transition in that career. During the development phases, family support, the difficulties of maintaining a professional level and the stress from career planning were singled out as the most important factors to the development process of the sport. It was concluded Conexões: revista da Faculdade de Educação Física da UNICAMP, Campinas, v. 8, n. 3, p. 84-103, set./dez. 2010. ISSN: 1983-9030
\end{abstract}


that the development of athlete's career was assisted, in all the phases, with support (financially and/or motivation) from their families.

KEY-WORDS: Development phases; Sports careers; Soccer. 


\section{INTRODUÇÃO}

O futebol é o esporte com o maior número de praticantes em todo o mundo. A Federação Internacional das Associações de Futebol (FIFA) estima mais de 240 milhões de jogadores ativos em 204 países. ${ }^{1}$ Considerado em muitos países como a principal modalidade esportiva, pode ser praticada por pessoas de todas as idades e níveis sociais. Analisando o contexto nacional, o futebol é visto, por jovens e seus familiares, como uma chance de ascensão social e profissional, diante da realidade de baixo nível socioeconômico que muitos desses atletas se encontram. ${ }^{2}$

Avaliar as diferentes fases de transição da carreira esportiva de atletas tem sido objeto de estudo de diferentes pesquisadores ${ }^{3-5}$ que buscam conhecer os elementos facilitadores e dificultadores existentes neste percurso e também propor modelos teóricos de entendimento destas variáveis ligados as fases da carreira esportiva. ${ }^{6-8}$

Um modelo de transição de carreira que pode ser aplicado a qualquer fase da carreira esportiva de um atleta é o Modelo Conceitual da Transição de Carreira ${ }^{6}$ que integra, além da informação teórica, a investigação empírica. Utilizando este tipo de método de estudo é possível avaliar as características da transição que incluem a duração da carreira esportiva, as mudanças de posição social, o grau de estresse, os desafios enfrentados e a percepção de estresse no momento de transição. ${ }^{9}$ Estudar as causas que levam os atletas a se retirarem do esporte é de relevância fundamental para a compreensão de como se conduz o processo de transição da carreira esportiva e a reinserção desse indivíduo na sociedade, além de ser fundamental para minimizar os efeitos e transtornos causados pelo término da carreira.

Distinguem-se dois tipos de carreira no futebol, as que se encerram de forma precoce, como por exemplo, atletas acometidos de graves lesões, ${ }^{1,10-11} \mathrm{e}$ as extensas, caracterizadas por atletas que se aposentam próximo dos 40 anos de idade. ${ }^{9}$

A carreira esportiva é composta de uma sequiência de sucessivas fases, com períodos de transição, ou seja, uma mudança de uma das fases da carreira para outra, sendo acompanhadas por concomitantes alternâncias nas mais variadas características do atleta, entre elas, as psicológicas e sociais, sendo necessário o apoio adequado para lidar 
com cada momento. ${ }^{12}$ Vários autores identificaram fases de desenvolvimento da carreira esportiva, realizando pesquisas acerca das mesmas. ${ }^{13-17}$ Sendo que Salmela ${ }^{14}$ (1994) identifica três, a iniciação, o desenvolvimento e o término.

O período compreendido como iniciação esportiva se caracteriza como um período de formação, onde se procura desenvolver bases que permitam aos atletas alcançar, futuramente, os tão esperados resultados. ${ }^{18} \mathrm{O}$ desenvolvimento é caracterizado por longos períodos de formação (física, técnico, tática e psicológica) envolvendo os treinamentos e as competições. ${ }^{14} \mathrm{O}$ término, ou abandono da carreira, pode estar relacionado com o esgotamento da motivação intrínseca do atleta ou com a ausência do trabalho de base essencial para obter resultados de alto rendimento na idade adulta, devido à orientação exclusiva para as vitórias durante o processo de formação, ${ }^{18}$ além disso, pode relacionar-se com alto índice de lesões ${ }^{1,11}$ ou a idade cronológica avançada. ${ }^{9}$

Wylleman, Lavallee e Alfermann ${ }^{4}$ afirmam que o término da carreira esportiva é, na maioria das vezes, multifatorial e não apenas causado por um fator isolado, sendo freqüentemente, uma combinação de fatores individuais e influências sociais. Os mesmos autores citam que a idade cronológica, a fadiga psicológica, os problemas de relacionamento, novos interesses pessoais, os problemas de contusão ou saúde, o declínio no rendimento e o fato dos atletas não serem mais selecionados para os jogos são exemplos de alguns desses fatores.

Em seu estudo, Samulski et al. ${ }^{19}$ analisaram as diferentes fases de transição da carreira esportiva de seis ex-atletas brasileiros de alto rendimento de diferentes modalidades esportivas. Os autores identificaram fatores relevantes ao desenvolvimento de cada fase das carreiras desses atletas, por meio de entrevistas semi-estruturadas. Os principais resultados foram o apoio da família em todas as fases de desenvolvimento da carreira desses atletas e que o término da carreira foi planejado, para maioria dos atletas investigados. O estudo concluiu que fatores como a retomada dos estudos e a busca pela formação acadêmica, uma maior dedicação a suas famílias e a inserção em outros grupos sociais fora do contexto esportivo foram fundamentais para uma transição adequada, sem seqüelas e que permitiu a esses 
atletas terminar suas carreiras esportivas e retornar a sociedade em busca de novos desafios pessoais e profissionais.

Agresta, Brandão e Barros Neto, ${ }^{9}$ analisaram o término da carreira de 79 ex-atletas de basquete e vôlei, e por meio de uma entrevista semi-estruturada observaram que 75,9\% encerraram a carreira de forma espontânea, onde, a idade $(49,4 \%)$ e outros interesses (43\%) foram os motivos mais relevantes. Os sentimentos mais latentes em relação ao término de carreira foram à tristeza $(50,6 \%)$ e a conformidade $(36,7 \%)$. A conclusão do estudo foi que os atletas tiveram longas carreiras, porém no momento do término das mesmas o principal sentimento foi o de tristeza.

Portanto, o presente estudo tem como objetivo investigar, de forma retrospectiva, os principais aspectos relacionados à cada fase de transição da carreira esportiva de exatletas de futebol.

\section{MÉTODO}

\section{Amostra}

Participaram deste estudo 25 ex-atletas de futebol do gênero masculino, alfabetizados, com idade média de 49,20 9,61 anos, que atuaram em grandes clubes profissionais do Brasil e que atualmente residem em Belo Horizonte. O tempo de experiência médio desses atletas, como profissionais, em seus respectivos clubes foi de 12,30 \pm 7,01 anos, os mesmos realizaram, diariamente, 3,71 $\pm 1,34$ horas de treinamento. Os atletas iniciaram à prática do futebol de forma sistematizada com 12,72 $\pm 2,94$ anos, além disso, todos os entrevistados foram atletas federados à Confederação Brasileira de Futebol (CBF) e que participaram de competições nacionais e internacionais, e atualmente são filiados a AGAP-MG (Associação de Garantia ao Atleta Profissional de Minas Gerais).

\section{Instrumento}


Este estudo utilizou um questionário semi-estruturado composto por 45 questões, desenvolvido a partir do Questionário de Transição no Futebol - Amador/Profissional ${ }^{20}$ O questionário é constituído de cinco partes:

1- Dados gerais e escolaridade (6 questões);

2 - Formação esportiva inicial (15 questões);

3- Contexto familiar e social (10 questões);

4 - Planejamento da carreira (6 questões);

5 - Contexto do Futebol (8 questões), sendo composto por questões de múltipla escolha, pontuadas em escala likert de cinco pontos (que varia de 0-nenhum a 4-altíssimo) e questões abertas, onde o voluntário responderia sobre o tópico abordado.

\section{Procedimentos}

Foi realizado um contato inicial com a Associação da Garantia de Atletas Profissionais de Futebol (AGAP) e com a Secretaria Municipal Adjunta de Esportes (SMAES), da Prefeitura de Belo Horizonte (PBH) com o objetivo de conseguir o apoio institucional das mesmas e explicar os objetivos do estudo.

Com o consentimento das instituições envolvidas, foi realizado um contato telefônico com os ex-atletas, inicialmente convidando-os para participar do estudo, e posteriormente, para agendar uma data para a realização da coleta dos dados e assinatura do Termo de Consentimento Livre e Esclarecido (TCLE).

Todos os ex-atletas residentes em Belo Horizonte e filiados a AGAP que declararam interesse em participar da pesquisa foram entrevistados.

As coletas foram executadas pelo mesmo pesquisador, em uma sala de reunião de cada Regional da PBH, sem pressão de tempo. Durante as coletas, os voluntários gozaram de total liberdade para abandonar a pesquisa, sem qualquer prejuízo ou inconveniência. Os ex-atletas foram informados que durante o preenchimento do questionário, poderiam sanar quaisquer dúvidas. A duração média das coletas foi de 50 minutos em média. 
$\mathrm{O}$ anonimato dos participantes foi preservado. Este estudo está dentro das normas estabelecidas pelo Conselho Nacional de Saúde $^{21}$ e pelo Tratado de Ética de Helsinki (1996), envolvendo pesquisas com seres humanos.

\section{Análise Estatística}

Todos os procedimentos foram calculados pelo pacote estatístico SPSS (Statistical Package for Social Sciences) para Windows® 2000, versão 12.0.

Foi utilizada uma análise descritiva composta por média e desvio padrão. Para os dados categóricos ou nominais, foi utilizada distribuição de frequência (percentual).

\section{RESULTADOS}

De acordo com o objetivo proposto neste estudo, os resultados referentes à fase inicial, desenvolvimento e término da carreira esportiva serão apresentados separadamente.

\section{Fase inicial da carreira}

Em relação à fase inicial da prática esportiva dos atletas, destaca-se na tabela 1 a existência de um baixo nível acadêmico dos atletas (58\% - ensino fundamental incompleto), enquanto que em relação à renda familiar 56\% dos atletas estavam inseridos em um contexto familiar no qual a renda era inferior a dois salários mínimos. Os resultados referentes à renda familiar e nível de escolaridade dos atletas nesta primeira fase serão apresentados a seguir.

Tabela 1: Nível de escolaridade e renda familiar durante a fase inicial da carreira esportiva

\begin{tabular}{cccc}
\hline Escolaridade & $\%$ & Renda Familiar & $\%$ \\
\hline Ensino fundamental & 42 & $\leq 2$ salários min. & 56 \\
Ensino fundamental & 58 & até 3 salários min. & 16 \\
$\quad$ incompleto & & até 4 salários min. & 8 \\
& & $\geq 5$ salários min. & 20 \\
\hline
\end{tabular}

Conexões: revista da Faculdade de Educação Física da UNICAMP, Campinas, v. 8, n. 3, p. 84-103, set./dez. 2010. ISSN: 1983-9030 
Como aspectos mais relevantes destacados pelos ex-atletas de futebol durante esta fase, destacam-se onde foi o aprendizado do futebol, quem os apoiou neste momento de início, de onde proviam suas amizades e se nesta fase já existia a preocupação com o desenvolvimento da carreira esportiva. A tabela 2 apresenta os aspectos iniciais mais relevantes.

Tabela 2: Aspectos destacados no início da carreira esportiva

\begin{tabular}{cccc}
\hline \multicolumn{4}{c}{ INÍCIO DA CARREIRA } \\
\hline Aprendizado & Apoio & Ambiente social & $\begin{array}{c}\text { Planejamento } \\
\text { da carreira }\end{array}$ \\
$\begin{array}{c}\text { Em campos de várzea } \\
(56 \%)\end{array}$ & $\begin{array}{c}\text { Família / Amigos } \\
(80 \%)\end{array}$ & $\begin{array}{c}\text { Amigos da rua e/ou } \\
\text { bairro }(84 \%)\end{array}$ & Não planejaram \\
Na rua (32\%) & Ninguém (20\%) & Parentes (8\%) & $(100 \%)$ \\
Clubes (12\%) & & Escola (8\%) & \\
\hline
\end{tabular}

Fase de desenvolvimento da carreira

Na tabela 3 observa-se que o principal fator de suporte que os atletas recebiam dos clubes estava ligado a situações de lesões, tendo no apoio familiar a base para prosseguirem suas carreiras. Os atletas avaliados também destacam que a motivação e prazer pelo esporte foram fundamentais para eles durante a sua carreira esportiva.

Tabela 3: Aspectos destacados durante a carreira esportiva

\begin{tabular}{|c|c|c|c|c|c|}
\hline \multicolumn{6}{|c|}{ DESENVOLVIMENTO DA CARREIRA } \\
\hline Suporte do clube & $\begin{array}{l}\text { Suporte de } \\
\text { pessoas }\end{array}$ & $\begin{array}{c}\text { Tipo e apoio } \\
\text { (pessoas) }\end{array}$ & $\begin{array}{l}\text { Planejamento } \\
\text { da carreira }\end{array}$ & $\begin{array}{c}\text { Dificuldades } \\
\text { encontradas } \\
\text { para dar } \\
\text { continuidade a } \\
\text { carreira } \\
\end{array}$ & $\begin{array}{c}\text { Ambiente } \\
\text { social durante } \\
\text { a carreira } \\
\text { profissional }\end{array}$ \\
\hline $\begin{array}{l}\text { Tratamento de } \\
\text { lesões }(48 \%)\end{array}$ & Família $(56 \%)$ & $\begin{array}{c}\text { Motivacional } \\
(74 \%)\end{array}$ & & Lesões $(28 \%)$ & $\begin{array}{l}\text { Do futebol } \\
\quad(44 \%)\end{array}$ \\
\hline $\begin{array}{c}\text { Aspectos } \\
\text { financeiros }(20 \%)\end{array}$ & $\begin{array}{l}\text { Amigos } \\
(24 \%)\end{array}$ & $\begin{array}{l}\text { Financeiro } \\
(20 \%)\end{array}$ & & $\begin{array}{c}\text { Financeiro } \\
(24 \%)\end{array}$ & Família $(28 \%)$ \\
\hline $\begin{array}{l}\text { Planejamento da } \\
\text { carreira }(16 \%)\end{array}$ & $\begin{array}{c}\text { Treinadores } \\
(20 \%)\end{array}$ & Outros $(6 \%)$ & $\begin{array}{c}\text { Planejaram } \\
(100 \%)\end{array}$ & $\begin{array}{c}\text { Estrutural } \\
(20 \%) \\
\text { Dificuldade } \\
\text { para estudar } \\
(12 \%)\end{array}$ & $\begin{array}{c}\text { Amigos - rua / } \\
\text { bairro }(24 \%)\end{array}$ \\
\hline Outros $(16 \%)$ & & & & Outros $(16 \%)$ & Outros $(4 \%)$ \\
\hline
\end{tabular}

Conexões: revista da Faculdade de Educação Física da UNICAMP, Campinas, v. 8, n. 3, p. 84-103, set./dez. 2010. ISSN: 1983-9030 
Fase de término da carreira

A tabela 4 mostra a preocupação de, aproximadamente, metade do grupo em planejar o término da carreira esportiva, sendo a família a principal fonte de apoio para tal transição. Observa-se que metade mais da metade do grupo continuou, de alguma forma, envolvida no ambiente esportivo. As lesões, a idade avançada e a preocupação com a família foram os principais motivos para o término da carreira esportiva.

Tabela 4: Aspectos destacados no término da carreira esportiva

\begin{tabular}{|c|c|c|c|c|c|}
\hline \multicolumn{6}{|c|}{ TÉRMINO DA CARREIRA } \\
\hline $\begin{array}{l}\text { Transição da } \\
\text { carreira }\end{array}$ & Apoio & $\begin{array}{l}\text { Ambiente } \\
\text { social }\end{array}$ & $\begin{array}{l}\text { Planejamento } \\
\text { do término }\end{array}$ & $\begin{array}{c}\text { Auxílio para } \\
\text { o término }\end{array}$ & $\begin{array}{c}\text { Motivos para } \\
\text { o término }\end{array}$ \\
\hline \multirow{2}{*}{$\begin{array}{c}\text { Atividades } \\
\text { relacionadas ao } \\
\text { futebol }(60 \%)\end{array}$} & $\begin{array}{c}\text { Família } \\
(56 \%)\end{array}$ & Família $(40 \%)$ & \multirow{2}{*}{$\begin{array}{l}\text { Planejaram } \\
(52 \%)\end{array}$} & \multirow{2}{*}{ Família (42\%) } & Lesões $(32 \%)$ \\
\hline & $\begin{array}{c}\text { Amigos } \\
(32 \%)\end{array}$ & $\begin{array}{c}\text { Amigos - rua / } \\
\text { bairro }(28 \%)\end{array}$ & & & $\begin{array}{c}\text { Idade avançada } \\
(20 \%)\end{array}$ \\
\hline \multirow{3}{*}{$\begin{array}{l}\text { Atividades fora } \\
\text { do ambiente } \\
\text { esportivo (40\%) }\end{array}$} & \multirow{3}{*}{$\begin{array}{l}\text { Outros } \\
(12 \%)\end{array}$} & $\begin{array}{l}\text { Do futebol } \\
\quad(24 \%)\end{array}$ & \multirow{3}{*}{$\begin{array}{c}\text { Não planejaram } \\
(48 \%)\end{array}$} & $\begin{array}{l}\text { Treinador } \\
(34 \%)\end{array}$ & $\begin{array}{c}\text { Dedicação à } \\
\text { família }(20 \%)\end{array}$ \\
\hline & & Outros $(8 \%)$ & & Outros $(24 \%)$ & $\begin{array}{l}\text { Falta de } \\
\text { motivação } \\
(16 \%)\end{array}$ \\
\hline & & & & & Outros (12\%) \\
\hline
\end{tabular}

\section{DISCUSSÃO}

\section{Dados demográficos do estudo}

De acordo com os dados demográficos, os ex-atletas apresentavam uma carga

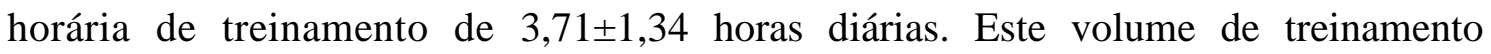
dificultou o rendimento acadêmico dos atletas, já que 58\% não completaram o ensino fundamental (tabela 1), Além disso, os atletas apresentaram uma carreira com tempo médio de 12,30 \pm 7,01 anos. Esses resultados confirmam os resultados encontrados por Wyllemann, Lavallee e Alfermann ${ }^{4}$ em sua revisão de literatura analisando a perspectiva européia e Samulski et al. ${ }^{19}$ que ao analisar a transição da carreira esportiva de seis ex-atletas de alto rendimento de várias modalidades esportivas identificaram que atletas inseridos no esporte competitivo têm dificuldade de conciliar a vida acadêmica com a vida esportiva, abandonando momentaneamente a primeira. Além do apresentado, Donnelly ${ }^{22}$ elucida que muitos dos atletas que param de estudar devido às exigências da carreira esportiva, se arrependem no momento que encerram a mesma, Conexões: revista da Faculdade de Educação Física da UNICAMP, Campinas, v. 8, n. 3, p. 84-103, set./dez. 2010. ISSN: 1983-9030 
pois na maioria das vezes eles não possuem outro ciclo de convivência social que não seja o meio esportivo.

\section{Fase inicial da carreira}

Compreender a realidade em que o atleta está inserido no início de sua prática é fundamental para contextualizar todo o desenvolvimento de sua carreira, dessa forma, ao analisar a renda das famílias dos atletas, destaca-se que $56 \%$ dos atletas entrevistados apresentavam renda familiar igual ou inferior a dois salários mínimos (tabela 1), o que pode justificar a dificuldade desses atletas se manterem na escola, já que o abandono dos estudos em detrimento de uma oportunidade de mudança de vida econômica e social da família é vislumbrada pelo atleta de futebol. Este resultado corrobora com Moraes, Rabelo e Salmela, ${ }^{23}$ que analisaram a influência da família em jovens praticantes de futebol, os resultados apontaram que movidos por uma motivação intrínseca muito elevada e pela chance de melhoria do nível econômico de suas famílias, as crianças continuavam na prática do futebol.

De acordo com os resultados apresentados na tabela 2, destaca-se que a maioria dos exatletas iniciou a prática esportiva em campos de várzea e/ou na rua $(88 \%)$ e apenas $12 \%$ aprendendo a jogar futebol em escolas esportivas. Estes resultados não corroboram com os resultados encontrados por Marques e Samulski, ${ }^{2}$ esses autores relatam em um estudo recente um aumento do número de crianças que aprendem a jogar futebol em escolas esportivas, os autores identificaram que $33,9 \%$ dos atletas de categoria de base no estudo iniciaram suas carreiras neste segmento esportivo.

O estudo reforça que este aumento do número de atletas formados em escolas esportivas

é provocado principalmente pelas questões urbanas de expansão das metrópoles, aumento da demanda imobiliária, falta de segurança para se jogar na rua, diminuição dos espaços públicos para a prática do futebol e dos campos de várzea.

Em relação ao apoio recebido para o início da prática esportiva (tabela 2), 80\% dos atletas citaram que este apoio estava relacionado à família/amigos. Desta forma, estes resultados corroboram com alguns estudos que avaliaram a presença dos amigos e da família nesta fase. Bloom ${ }^{13}$ (1985) afirma que nos anos iniciais a presença da família 
como fonte de apoio financeiro e emocional é fundamental para a inserção/manutenção da criança na modalidade esportiva.

Outro ponto a ser destacado considera a importância do convívio social dos amigos de infância e adolescência, os ex-atletas avaliados destacam a influência destas pessoas no início de suas carreiras esportivas (84\%), este resultado é semelhante ao obtido no estudo de Samulski et al., ${ }^{19}$ que constatou a importância dos grupos de amigos para a iniciação e permanência no esporte. McCarthy e Jones ${ }^{24}$ realizaram um estudo qualitativo com 45 crianças, no qual o objetivo era examinar quais as fontes que proporcionavam o prazer e o desprazer em praticar atividades esportivas nos anos iniciais. Os principais resultados indicaram que as fontes prazerosas para os praticantes foram: envolvimento social, relação com os amigos e um envolvimento com o ambiente esportivo. Já as principais fontes de desprazer foram cobranças excessivas dos pais e feedback negativo por parte dos treinadores.

Os ex-atletas avaliados, que praticaram futebol profissional nas décadas de setenta e oitenta, relatam que nesta fase inicial não pensavam no planejamento da carreira esportiva, pois os motivos de permanência e pratica do esporte não estavam associados a questões relacionadas à profissionalização. Entretanto Samulski et al. ${ }^{19}$ retrata que atualmente as crianças já nesta fase inicial, tem um despertar precoce para a idéia de profissionalização dentro do futebol, os autores argumentam que fatores ligados a mídia e a possibilidade de ascensão social e financeira tem influenciado e direcionado o pensamento das crianças e o planejamento por parte dos responsáveis legais para este tipo de pensamento. Esta especialização e cobrança precoce por rendimento pode causar danos a saúde dos pré-puberes. ${ }^{24}$

\section{Fase de desenvolvimento da carreira}

Em relação ao suporte do clube para os atletas durante este período (tabela 3), observase que a atenção oferecida ao atleta em relação à recuperação de lesões (48\%), ao planejamento da carreira a longo prazo (16\%) e o apoio financeiro (20\%) foram os principais aspectos encontrados no estudo. 
Tais resultados corroboram com o estudo a respeito dos recursos contextuais de Côté et al. ${ }^{25}$ Esses recursos são importantes ferramentas no universo do atleta e são decisivos na formação do mesmo. Os recursos materiais possibilitam o treinamento e a recuperação de atletas em qualquer condição e os financeiros, viabilizam a participação e a possibilidade de execução da atividade na melhor estrutura possível de salários. ${ }^{26,27}$ Tais recursos servem como apoio e motivação para a continuidade da prática e para a melhoria do desempenho atlético.

Ao se analisar a origem do apoio que os atletas tiveram durante esta fase, os resultados indicam que a família (56\%), os amigos (24\%) e os treinadores (20\%) foram os responsáveis por apoiar os atletas principalmente nos aspectos motivacionais (74\%) e financeiros $(20 \%)$.

Estes resultados confirmam os estudos de Bloom; ${ }^{13}$ Csikszentmihalyi; Rathunde; Whalen, ${ }^{28}$ Côté ${ }^{15}$; Holt; Dunn, ${ }^{29}$ nos quais, os autores afirmam que os pais, nesta fase, contribuem principalmente com o apoio financeiro/motivacional, como despesas com materiais, viagens e melhores condições de treinamento, se tornando fundamentais para o desenvolvimento de seus filhos. Tal apoio garante a manutenção da atividade dos filhos em relação aos mais variados aspectos, como os motivacionais ${ }^{30}$, a realização e o comprometimento. $^{31}$

Em relação às principais influências no ambiente social dos atletas, os amigos relativos, ainda, de amizades da infância (24\%), e do ambiente futebolístico (44\%) foram citados como fundamentais para a continuidade da modalidade esportiva (tabela 3). Tais resultados corroboram com o estudo de Bruner, Munroe-Chandler e Spink ${ }^{32}$ analisaram a transição do segundo para a terceira fase de desenvolvimento de oito jogadores de hockey. Os resultados demonstraram que os atletas tiveram uma relação direta com treinadores e companheiros de time (amigos), sendo esta relação primordial para o desenvolvimento dos atletas.

A partir desta fase, observa-se que todos os atletas apresentam algum tipo de preocupação em relação ao planejamento da carreira esportiva, já que os mesmos abandonaram os estudos e acreditam que todo o sucesso, inclusive o financeiro, está 
diretamente relacionado ao desempenho do futebol. Esta constatação confirma o encontrado no trabalho de Marques e Samulski ${ }^{2}$ que identificaram que os atletas têm uma preocupação razoável em relação ao planejamento de suas atividades esportivas a longo prazo, com exceção das atividades acadêmicas.

A incidência de lesões (28\%), a falta de estrutura (20\%) e a falta de recursos financeiros (24\%) foram às principais dificuldades encontradas pelos atletas para dar continuidade aos treinamentos com altos níveis de excelência.

As lesões são responsáveis pela interrupção da carreira de atletas de várias modalidades esportivas. ${ }^{1,9-119}$ No estudo realizado por Rocha e Santos ${ }^{5}$ com 16 atletas de atletismo a respeito do abandono da carreira esportiva no período compreendido entre a transição da categoria juvenil para o adulto, as lesões e a falta de infra-estrutura foram destacados como fatores determinantes para o abandono da modalidade.

\section{Fase de término da carreira}

De acordo com a Tabela 4, após o término da carreira esportiva, 60\% dos atletas se mantiveram no ambiente esportivo por meio de algum vínculo e $40 \%$ procuraram por atividades que não estavam correlacionadas ao futebol. De acordo com Brandão et $\mathrm{al}^{33}$ os atletas tendem a lidar melhor com o período de transição de suas carreiras quando continuam envolvidos, de alguma forma, com o ambiente esportivo.

Da mesma forma como aconteceu na fase inicial, à família é o principal ponto de apoio do atleta para encerrar a carreira esportiva (56\%), na seqüência aparece o apoio dos amigos (32\%). No auxílio que envolve não somente o apoio mais ações concretas de orientação e ajuda profissional, os ex-treinadores (34\%), foram mencionados como os principais responsáveis pela amostra avaliada.

Estes resultados confirmam os encontrados em diversas pesquisas que afirmam que a presença da família, apoiando de todas as formas possíveis em todos os momentos da carreira, inclusive o término, é fundamental para o desenvolvimento adequado dos atletas. $^{13,15-16,19,27}$

Conexões: revista da Faculdade de Educação Física da UNICAMP, Campinas, v. 8, n. 3, p. 84-103, set./dez. 2010. ISSN: 1983-9030 
Os principais motivos citados para o término da carreira esportiva foram, excessivas lesões (32\%), idade cronológica (20\%), necessidade de uma dedicação maior à família (20\%) e a falta de motivação para se manter na excelência esportiva (20\%). Os resultados referentes às lesões confirmam em parte os resultados encontrados por Rocha e Santos $^{5}$ e Samulski et al. ${ }^{19}$ que identificaram como desencadeadores do término da carreira esportiva, entre outros fatores, o aumento no número de lesões/ contusões e a demora no processo de recuperação.

Os dados relacionados à idade avançada e outros interesses (dedicação à família) corroboram com o trabalho de Agresta, Brandão e Barros Neto ${ }^{9}$ no qual avaliaram 79 ex-atletas de alto rendimento e identificaram que 49,4\% abandonaram a carreira por motivo de idade e $43 \%$ por motivos relacionados à outros interesses pessoais. Ao se analisar a falta de motivação para a prática esportiva, os resultados confirmam o que Ericsson, Krampe e Tesch-Römer ${ }^{34}$ apontam em seu trabalho como uma das principais restrições à prática deliberada, pois a falta de motivação intrínseca pode promover o abandono da modalidade.

De acordo com a tabela 4, $52 \%$ planejaram o término da carreira, enquanto que $48 \%$ não tiveram tal preocupação. Estes resultados podem ser justificados devido ao surgimento de lesões ou à perda e motivação dos atletas. Para Brandão et al. $^{33}$ a transição da carreira esportiva nesta última fase se caracteriza pela aposentadoria no esporte e a transição para uma nova fase de vida, o que vai exigir do indivíduo um novo planejamento orçamentário e financeiro, um planejamento pessoal e profissional sobre as metas pós carreira esportiva. Os autores reforçam que quando esta operação é feita, se necessário, com o auxílio de profissionais da área de gestão de carreiras, para que o processo de adaptação a nova fase de vida provoque um mínimo possível de celeumas na vida do ex-atleta.

\section{CONCLUSÃO}

Conclui-se, a partir do objetivo de investigar os principais aspectos relacionados à cada fase de transição da carreira esportiva de ex-atletas de futebol, que o desenvolvimento 
da carreira dos atletas foi assistido, em todas as fases, pelo apoio (financeiro e / ou motivacional) de suas famílias.

$\mathrm{Na}$ fase inicial da carreira, o apoio da família e dos amigos foi fundamental para a inserção e manutenção da prática esportiva, já que o aprendizado ocorreu, em sua maioria, nos campos de várzea e na rua, o que pode ser justificado pelo período em que este aprendizado ocorreu, pois a idade dos voluntários demonstra que este aprendizado ocorreu entre as décadas de 1970 e 1980. Nos dias atuais, o aprendizado de algumas crianças ainda ocorre nas ruas e em campos de várzea, mas o que se observa, devido o crescimento das cidades, é um aumento do número de crianças que aprendem jogar futebol nas escolas esportivas. ${ }^{2}$

$\mathrm{Na}$ fase de desenvolvimento, destaca-se a preocupação que os atletas apresentaram em relação ao planejamento de suas carreiras, em como as mesmas deveriam ser conduzidas. Tal preocupação se deu, em parte, pela despreocupação dos atletas em relação à vida acadêmica, dessa forma, o futebol era visto como uma esperança de tentar reverter a realidade financeira das famílias em que alguns desses atletas estavam inseridos.

Na fase do término da carreira, última fase, dois pontos são relevantes, o primeiro é o motivo pelo qual os atletas abandonaram as carreiras esportivas e o outro fator, diretamente relacionado com o primeiro é se houve ou não o planejamento para este término. Os principais motivos citados para o término da carreira esportiva foram, excessivas lesões, idade cronológica avançada, necessidade de uma dedicação maior à família e a falta de motivação para se manter na excelência esportiva. Se o motivo fosse transversal, como uma lesão muito grave (32\%), era claro a não preocupação com o planejamento do término da carreira.

Este estudo limitou-se a avaliar o contexto de ex-atletas de futebol que hoje residem em Belo Horizonte, entretanto cabe ressaltar a necessidade de outros estudos em outras regiões do país, devido aos contrastes socioculturais e econômicos de cada região, objetivando traçar um mapa mais fidedigno da realidade do ex-atleta de futebol no Brasil. 


\section{REFERÊNCIAS}

${ }^{1}$ TIMPKA, T.; RISTO, O.; BJORMSJO, M. Boys soccer league injuries: a communitybased study of time-loss from sports participation and long-term sequelae. Eur J Pub Health, v. 18, n. 1, p. 19-24, 2007.

${ }^{2}$ MARQUES, M. P.; SAMULSKI, D. M. Análise da carreira esportiva de jovens atletas de futebol na transição da fase amadora para a fase profissional: escolaridade, iniciação, contexto sócio-familiar e planejamento da carreira. Rev Bras Educ Fís Esporte, v. 23, n. 2, p. 103-119, 2009.

${ }^{3}$ SINCLAIR, D. A.; ORLICK, T. Positive transitions from high-performance sport. The Sport Psychologist, v. 7, p. 138-150, 1993.

${ }^{4}$ WYLLEMANN, P.; ALFERMANN, D.; LAVALLEE, D. Career transitions in sport: European perspectives. Psych Sport Exerc, v. 5, p. 7-20, 2004.

${ }^{5}$ ROCHA, P. G. M.; SANTOS, E. S. O abandono da modalidade esportiva na transição da categoria juvenil para adulto: Estudo com talentos do atletismo. Revista da Educação Física, v. 21, n. 1, p. 69-77, 2010.

${ }^{6}$ TAYLOR, J.; OGILVIE, B. C. A conceptual model of adaptation to retirement among athletes. J Appl Sport Psychol, v. 6, p. 1-20, 1994.

${ }^{7}$ STAMBULOVA, N. Sports career psychological models and its applications. In: CONGRESSO MUNDIAL DE PSICOLOGIA DO ESPORTE, 9., Israel, 1997. Proceedings... Israel, 1997.

${ }^{8}$ STAMBUlOVA, N., CHEREMNYH, A. D. Transitions of disabled athletes. In: CONGRESSO EUROPEU DE PSICOLOGIA DO ESPORTE, 10. 1999, Praga. Proceedings... Praga, 1999. p. 184-186. 
9 AGrestA, M. C.; BRANDÃO, M. R. F.; BARROS NETO, T. L. Causas e conseqüências físicas e emocionais do término de carreira esportiva. Rev Bras Med Esport, v. 14, n. 6, p. 504-508, 2008.

${ }^{10}$ FULLER, C. W. et al. Consensus statement on injury definitions and data collection procedures in studies of football (soccer) injuries. British J Sports Med, v. 40, p. 193201, 2006.

${ }^{11}$ COUTINHO, R. M. S. Influência da sobrecarga e das lesões articulares no estado de saúde atual das articulações do joelho e tornozelo, em antigos profissionais de futebol. 2009. Dissertação (Mestrado) - Faculdade de Desporto, Universidade do Porto, Portugal, 2009.

12 ALFERMANN, D. Career transition and concomitant changes in athletes. In: WORLD CONGRESS OF SPORT PSYCHOLOGY, 11., 2005, Sidney, Austrália. Proceedings ... Sidney: International Society of Sport Psychology; 2005.

${ }^{13}$ BLOOM, B. S. Developing talent in young people. New York: Ballantine Books; 1985.

${ }^{14}$ SALMELA, J. H. Phases and transitions across sport careers. In: HACKFORT D. (Ed.). Psycho-social issues and interventions in elite sports. Frankfurt: Peter Lang, 1994. p.11-28.

${ }^{15}$ CÔTÉ, J. The influence of the family in the development of talent in sport. The Sport Psychologist, v. 13, p. 395-417, 1999.

${ }^{16}$ BAKER, J.; HORTON, S. A review of primary and secondary influences on sport expertise. High Ability Studies, v. 15, n. 2, p. 211-228, 2004.

17 COTÉ, J.; LIDOR, R.; HACKFORT, D. ISSP position stand: to sample or to specialize? Seven postulates about youth sport activities that lead to continued 
participation and elite performance. International Journal of Sport and Exercise Psychology, v. 9, p. 7-17, 2009.

${ }^{18}$ CAFRUNI, C.; MARQUES, A.; GAYA, A. Análise da carreira desportiva de atletas das regiões sul e sudeste do Brasil. Estudo dos resultados desportivos nas etapas de formação. Rev. Port. Cien. Desp, v. 6, n. 1, p. 55-64, 2006.

${ }^{19}$ SAMULSKI, D. M. et al. Análise das transições das carreiras esportivas de ex-atletas de alto nível. Motriz, v. 15, n. 2, p. 310-317, 2009.

${ }^{20}$ MARQUES, M. P. Análise da transição de carreira esportiva de atletas de futebol da fase amadora para a fase profissional. 2008. Dissertação (Mestrado em Ciências do Esporte) - Escola de Educação Física, Fisioterapia e Terapia Ocupacional, Universidade Federal de Minas Gerais, Belo Horizonte, 2008.

${ }^{21}$ BRASIL. Ministério da Saúde. Conselho Nacional de Saúde. Resolução 196/96 sobre pesquisas envolvendo seres humanos. Diário Oficial da União, Brasília, 16 out. 1996. p. 21082-21085.

${ }^{22}$ DONNELLY, P. Problems associated with youth involvement in high-performance sport. In: CAHILL, B. R.; PERAL, A. J. (Ed.). Intensive participation in children's sports. Champaign: Human Kinetics, 1993. p. 95-126.

${ }^{23}$ MORAES, L. C. C. A.; SAlMELA, J. H.; RABELO, A. S. Papel dos pais no desenvolvimento de jovens futebolistas. Psicologia: reflexão e crítica, v. 17, n. 2, p. 211-222, 2004.

${ }^{24}$ MCCARTHY, P. J.; JONES, M. V. A qualitative study of sport enjoyment in the sampling years. The Sport Psychologist, v. 21, p. 400-416, 2007.

${ }^{25}$ COTÉ, J. et al. The coaching model: a grounded assessment of expert gymnastic coaches' knowledge. Journal of Sport \& Exercise Psychology, v. 17, n. 1, p. 1-17, 1995. 
26 SAlMElA, J. H; MORAES, L. C. C. A. Coaching expertise: an international perspective. In: 10th world congress of sport psychology, 2001, Thessaloniki, Hellas: Christodoulidi, v. 3, p. 156-158, 2001

${ }^{27}$ MORAES, L. C. C. A.; SALMELA, J. H. Development of expertise: The role of coaching, families, and cultural contexts. In: STARKES, J. L.; ERICSSON, K. A. (Ed.). Expert performance in sports: advances in research on sport expertise. Champaign: Human Kinetics, 2003. p. 274-293.

${ }^{28}$ CSIKSZENTMIHALYI, M.; RATHUNDE, K.; WHALEN, S. Talent teenagers: the root of success and failure. Cambridge: Cambridge University Press; 1993.

${ }^{29}$ HOLT, N. L.; DUNN, J. G. H. Toward a grounded theory of the psychosocial competencies and environmental conditions associated with soccer success. Journal of Applied Sport Psychology, v. 16, n. 3, p. 199-219, 2004.

30 VERnACCHIA, R. A.; MCGUIRE, R. T.; REARDON, J. P.; TEMPLIN, D. P. Psychosocial characteristics of Olympic track and field athletes. International Journal of Sport Psychology, v. 31, n. 1, p. 5-23, 2000.

31 MALLET, C. J.; HANRAHAN, S. J. Elite athletes: why does the 'fire' burn so brightly. Psychology of Sport and Exercise, v. 5, n. 2, p. 183-200, 2004.

${ }^{32}$ BRUNER, M. W.; MUNROE-CHANDLER, K. J.; SPINK, K. S. Entry into the elite sport: a preliminary investigation into the transition experiences of rookie athletes. Journal of Applied Sport Psychology, v. 20, p. 236-252, 2008.

${ }^{33}$ BRANDÃO, M. R. F. et al.Causas e conseqüências da transição de carreira esportiva: uma revisão de literatura. Revista Brasileira de Ciência e Movimento, v. 8, n. 1, p. 48-58, 2000.

Conexões: revista da Faculdade de Educação Física da UNICAMP, Campinas, v. 8, n. 3, p. 84-103, set./dez. 2010. ISSN: 1983-9030 
${ }^{34}$ ERICSSON, K. A.; KRAMPE, R. T.; TESCH-ROMER, C. The role of deliberate practice in the acquisition of expert performance. Psychological Review, v. 100, n. 3, p. 363-406, 1993. 